\title{
Gender Difference in Care of Type 2 Diabetes
}

\author{
Aamod Dhoi Shrestha, ${ }^{1}$ Kalpana Kosalram, ${ }^{1}$ Vijayaprasad Gopichandran' \\ 'School of Public Health, SRM University, India.
}

\section{ABSTRACT}

Introduction: Biologically male and female have similar diabetes prevalence. Gender differences in the social structure bring differences in life style modifications and all other self care behaviors in type 2 diabetes. The primary purpose of this study was to assess the gender difference in care of type 2 diabetes in Western region, Nepal.

Methods: Hundred men and hundred women respondents participated in a cross-sectional study conducted in two hospitals in Pokhara, Nepal. A pre-tested questionnaire was administered to each of the respondents.

Results: Dry mouth $\left(\chi^{2}=3.977, \mathrm{P}=0.046\right)$ and abdominal pain $\left(\chi^{2}=3.840, \mathrm{P}=0.050\right)$ were reported as symptoms of diabetes in $51 \%$ and $31 \%$ women compared to $37 \%$ and $19 \%$ men respectively. The study revealed that women had low self-efficacy with respect to their diabetes care $(35 \%)$ in comparison to men (65\%). There was significant association between gender and diet practices which showed men have 0.328 (95\% CI: 0.184 - 0.585) times less chances of bad dietary practices compared to women. After adjusting for age, education, occupation and self-efficacy, men were less likely to have bad dietary practices (OR= $0.513,95 \% \mathrm{CI}: 0.266,0.992)$.

Conclusions: The result of this study provided evidence that there are gender differences in reporting of symptoms, mode of diagnosis and certain self-management behaviors. Therefore there is a need to design gender specific behavior change communication strategies for better management of type 2 diabetes.

Keywords: diabetes care; gender; self-efficacy; self-management.

\section{INTRODUCTION}

Diabetes mellitus is emerging as an epidemic of the $21^{\text {st }}$ century. About 366 million people around the world have diabetes and it is expected to increase to 552 million by 2030 in which more than $90 \%$ have type 2 diabetes. Three out of four people with diabetes live in low and middle-income countries where more than $80 \%$ of diabetes deaths occur. ${ }^{1}$

South-East Asia region harbors approximately onefifth of all adults with diabetes in the world. Current estimate indicates, 71.4 million people, have diabetes in 2011 , and it is expected to increase to 120.9 million by $2030 .^{2}$

Biologically male and female have similar diabetes prevalence. ${ }^{1}$ Gender differences in the social structure, gender differentials in diagnosis, access to care, access to medications and follow up, adherence to medications, life style modifications and all other self care behaviors

Correspondence: Aamod Dhoi Shrestha, School of Public Health, SRM University, India. Email: aamod.shrestha@gmail.com. 
are likely to introduce a dramatic contrast in the experiences of women with diabetes.

Several studies in the developed countries have shown that women have worse survival, higher risk of cardiac, renal complications and blindness compared to men. ${ }^{3}$ Limited studies have been conducted to explore gender differences in diabetes treatment and the situation is worse in developing countries.

Self management for people with chronic health problems is widely recognized as a necessary part of treatment. The patient is responsible for the day-to-day management of their illness. ${ }^{4}$ Self efficacy or confidence refers to the individual's belief in his or her capacity to perform self-management behaviors. ${ }^{5}$ The complex nature of diabetes self management makes it difficult for patients to practice. ${ }^{6}$ Self-management becomes more difficult for women in the developing countries where facts show that the position and status of women in society is worse and so is their health status as revealed by numerous health indices. ${ }^{7}$

The primary purpose of this study was to assess the gender differences in care, symptoms, mode of diagnosis and self-management of type 2 diabetes. There is shortage of such studies in Nepal where gender differences is highly rooted in social structure. So, it is important to explore differences between men and women in diagnosis, treatment and follow up, adherence to medications, life style modifications and self-management.

\section{METHODS}

A cross-sectional study was conducted at two super specialty hospitals, Western Regional Hospital and the Fishtail Hospital and Research Center located in Pokhara between the months of June and July 2012. The respondents were the diabetic patients visiting for the routine checkups in the outpatient department and diabetic education program conducted by the hospital weekly. Patient having severe conditions of disease and not able to speak, walk, and perform their daily routine were not included in the study. Those participants of age 20 years and above who had type 2 diabetes of at least one year history were included in the study.

As there was no data available regarding good selfmanagement behaviour $50 \%$ prevalence was assumed. Quota sapling technique was done calculating the sample size of 100 men and 100 women. They were administered a semi-structured questionnaire. The questionnaire was prepared in English language and Nepali language as well. It was pretested to 20 patients and necessary corrections were done. Pilot study participants were excluded from the main analysis.
The questionnaire consisted of two sections, the first section consisted of introduction and informed consent and the second section started with personal information, symptoms of diabetes, mode of diagnosis followed by date of diagnosis and treatment, selfmanagement and self-efficacy. Characteristics of the respondent were obtained from the first section with personal information age, gender, weight, height, marital status, education and occupation.

There were dichotomous questions to assess if the respondent had symptoms of diabetes like increased thirst, dry mouth, decreased appetite, nausea or vomiting, abdominal pain, frequent urination at night and morning headaches. Mode of diagnosis was obtained by asking each of the respondents whether they were diagnosed during routine screening test, due to symptoms, or due to complications. Recent fasting blood sugar and post prandial blood sugar reports were recorded.

Diabetes self-care activities questions were asked for each of the five domains diet, exercise, blood-glucose testing, foot-care, and smoking status. ${ }^{8}$ All the eleven questions were rated on the scale of zero to seven where zero denotes not following for even a single day and one to seven for the number of days in a week that the behavior is followed.

Diabetes Self efficacy scale was administered. ${ }^{9}$ Responses were rated on a scale of one to ten where the increasing number denotes the maximum confidence level. The scale consisted of eight items about confidence to perform diabetes self management behaviors. Both the scales were translated into Nepali. In order to validate the translation in Nepali, the recommendations of a professional English and Nepali teacher was obtained.

Data were processed using the Statistical Package for the Social Sciences (SPSS) version 17. Independent t-test was done to compare the overall self management scores between men and women. Chi square test was done to find the association between gender with diet and exercise. Multiple logistic regression analyses were performed for diet and exercise adjusting for age, education, occupation and self efficacy.

The study was clearly explained to the respondent and informed consent was taken from each of them before the personal interview. The study was also given expedited approval from the Institutional Review Board of School of Public Health, SRM University.

\section{RESULTS}

The average age of men and women were 57.76 (SD 12.24 ) and 55.26 (SD 11.18) years respectively. 
Majority of the men $(91 \%)$ and women $(78 \%)$ were married. The respondents were Hindu and Buddhist. They belonged to different ethnicity Brahmin, Chhettri, Janajati, Dalit, Madhesi and Newar. About $59 \%$ of the men and $27 \%$ of the women had education of $10^{\text {th }}$ grade and above, whereas $12 \%$ and $41 \%$ of men and women had no formal education. Nearly $70 \%$ of the women were home makers (Table 1).

\begin{tabular}{|c|c|c|c|}
\hline \multirow{2}{*}{$\begin{array}{l}\text { Characteristics } \\
\text { Mean Age }\end{array}$} & \multicolumn{2}{|c|}{ Male $(n=100)$} & \multirow{2}{*}{$\begin{array}{l}\text { Female } \\
(\mathbf{n}=100) \\
55.26 \pm 11.18\end{array}$} \\
\hline & 57.76 & \pm 12.24 & \\
\hline \multicolumn{4}{|l|}{$\begin{array}{l}\text { Marital Status \% } \\
\text { Never married }\end{array}$} \\
\hline Married & 2 & & 5 \\
\hline Divorced/ & 91 & & 78 \\
\hline Separated & 3 & & 0 \\
\hline Widowed & 4 & & 17 \\
\hline \multicolumn{4}{|l|}{ Religion \% } \\
\hline Hindu & 80 & & 76 \\
\hline Buddhist & 20 & & 24 \\
\hline \multicolumn{4}{|l|}{ Ethnicity \% } \\
\hline \multicolumn{4}{|l|}{ Brahmin/ } \\
\hline Chhettri & & 31 & 39 \\
\hline Janajati & & 25 & 35 \\
\hline Dalit & & 7 & 5 \\
\hline Terai/ Madhesi & & 6 & 0 \\
\hline Newar & & 31 & 21 \\
\hline \multicolumn{4}{|l|}{ Education \% } \\
\hline \multicolumn{4}{|l|}{ No Education } \\
\hline \multicolumn{4}{|l|}{ Primary } \\
\hline Education & 12 & & 41 \\
\hline Secondary & 26 & & 32 \\
\hline Education & 3 & & 0 \\
\hline SLC and Above & 59 & & 27 \\
\hline \multicolumn{4}{|l|}{ Occupation \% } \\
\hline \multicolumn{4}{|l|}{ Agriculture } \\
\hline Salary/ Wage & 8 & & 5 \\
\hline Own Business & 16 & & 6 \\
\hline Extended & 44 & & 15 \\
\hline Economic Work & 1 & & 0 \\
\hline Job Seeking & 1 & & 0 \\
\hline Household & 1 & & 71 \\
\hline Course & 0 & & 1 \\
\hline Student & 29 & & 2 \\
\hline No Work & & & \\
\hline
\end{tabular}

Dry mouth $\left(\chi^{2}=3.977, \mathrm{P}=0.046\right)$ and abdominal pain $\left(\chi^{2}=3.840, P=0.050\right)$ were reported as symptoms of diabetes in $51 \%$ of women and $37 \%$ of men and $31 \%$ of women and $19 \%$ of men respectively. Other symptoms like increased thirst, decreased appetite, nausea or vomiting, frequent urination and morning headache were not significantly different between men and women. While $37 \%$ of men were diagnosed with diabetes when testing for other illnesses, half of the women were diagnosed in that manner. About $45 \%$ men and $35 \%$ women were diagnosed as diabetic due to symptoms. This association was also statistically significant. Only $3 \%$ men and $1 \%$ women were diagnosed as diabetic during routine test. The average fasting blood sugar of the respondent was 121.51 (SD 42.7) among men and 138.59 (SD 70.89) among women and this difference was statistically significant applying the independent $t$-test $(t=-2.05, P=0.042)$.

The average self management score of general diet among men and women were 12.12 (SD 2.71) and 10.51 (SD 3.18) respectively which was statistically significantly different by independent t-test $(\mathrm{t}=3.850$, $\mathrm{P}=<0.05)$. The self management score of foot care among men and women were 9.65 (SD 4.32) and 8.04 (SD 4.67), $(\mathrm{t}=2.528, \mathrm{P}=0.012)$. Both men and women following seven days healthful eating plan were $67 \%$ and $40 \% .\left(\chi^{2}=14.664, P=0.01\right)$. Five servings of fruits and vegetables per day among men and women were $65 \%$ and $41 \%\left(\chi^{2}=12.695, \mathrm{P}=0.002\right)$. Men $(48 \%)$ were better in following the average monthly eating plan compared to women $(20 \%)\left(\chi^{2}=17.654\right.$, $\mathrm{P}=<0.05)$. More men (56\%) were following exercise for at least five days in a week compared to women $(37 \%)\left(\chi^{2}=7.328, P=0.026\right)$

There was no significant gender difference in the findings of seven days physical activity, fat consumption, foot care and inspection of shoes. Tobacco consumption percentage was higher in men including both smoked and chewed. The study revealed that women had low self-efficacy $(35 \%)$ in comparison to men $(65 \%)\left(\chi^{2}=\right.$ $18.00 \mathrm{P}=<0.05)$.

There was significant association between gender and diet practices which showed men have 0.328 times lesser chances of bad dietary practices compared to women (95\% Cl: $0.184-0.585)$. Further stratifying by self efficacy, the association between gender and diet practices was observed more among those with high self efficacy (OR $=0.346,95 \% \mathrm{Cl}: 0.145-0.826)$ and was not observed among those with low self efficacy (OR $=0.483,95 \% \mathrm{Cl}: 0.209-1.118)$. Self-efficacy was found as a confounding factor in the association between gender and good dietary practices.

Multiple logistic regression analyses were constructed to assess the association of diet and exercise (Table 2). Gender was still associated with good dietary practices when adjusted for age, education, occupation and self-efficacy. After adjusting for age, education 
and occupation and self efficacy, self-efficacy was significantly associated with exercise practices (Table 3).

\begin{tabular}{|lllll|}
\hline \multicolumn{5}{|c|}{ Table 2. Logistic regression model for diet. } \\
\hline Variable & $\begin{array}{l}\text { B coef- } \\
\text { ficient }\end{array}$ & $\begin{array}{l}\text { Exp } \\
\text { (B) }\end{array}$ & $95 \%$ Cl Lower & Upper \\
Age & 0.017 & 1.017 & 0.988 & 1.046 \\
Gender & 0.667 & 0.513 & 0.266 & 0.992 \\
Education & 0.280 & 1.323 & 0.997 & 1.757 \\
$\begin{array}{l}\text { Occupa- } \\
\text { tion }\end{array}$ & 0.005 & 1.006 & 0.869 & 1.164 \\
$\begin{array}{l}\text { Self-effi- } \\
\text { cacy }\end{array}$ & 0.683 & 1.981 & 1.019 & 3.850 \\
\hline
\end{tabular}

Omnibus test: $27.483, P-$ value: $<0.05$

\begin{tabular}{|lcccc|}
\hline \multicolumn{4}{|c|}{ Table 3. Logistic regression model for exercise. } \\
\hline Variable & $\begin{array}{l}\text { B coef- } \\
\text { ficient }\end{array}$ & Exp (B) & $\begin{array}{l}\text { 95\% Cl } \\
\text { Lower }\end{array}$ & Upper \\
Age & 0.047 & 1.048 & 1.017 & 1.080 \\
Gender & 0.377 & 1.458 & 0.724 & 2.935 \\
Education & 0.271 & 1.311 & 0.978 & 1.757 \\
Occupation & -0.069 & 0.933 & 0.804 & 1.083 \\
Self-efficacy & 1.432 & 4.186 & 2.082 & 8.414 \\
\hline
\end{tabular}

Omnibus test: $36.281, \mathrm{P}-$ value: $<0.05$

\section{DISCUSSION}

This study, to our knowledge is the first one to compare the gender differences in the clinical presentation, diagnosis, treatment and self management practices of type 2 diabetes in Nepal, a developing country. Previous studies have shown that biologically there is no difference between men and women in the prevalence and characteristics of type 2 diabetes. The difference is likely to be much wider in developing countries where the position of women in the society is still poor. In this context the gender differences in the care of type 2 diabetes becomes very important. This study looked at symptoms of diabetes, mode of diagnosis, blood sugar control levels and self management behaviors.

Women compared to men reported a higher incidence of dry mouth and abdominal pain as symptoms of diabetes. Other symptoms like increased thirst, decreased appetite, nausea or vomiting, frequent urination and morning headache did not show significant differences. It is not clear if this represents a biological phenomenon or whether it is a social phenomenon. Some studies have shown that women tend to present more with depressive somatic symptoms associated with diabetes while men were more likely to present with fatigue, muscle aches and sexual dysfunction. ${ }^{10}$ There have also been reports of abdominal pain being one of the common somatic manifestations of depression. ${ }^{11}$ This could be a possible explanation of abdominal pain being a common symptom in women with diabetes in this study. Studies with bigger sample sizes are required to assess the patterns of presentation of diabetes among women and men.

Men were likely to be diagnosed because of testing after onset of symptoms whereas women were more likely to be diagnosed when being tested for some other illness. This again highlights the gender differences in social structure in developing countries. Women attribute low priority to health and symptoms and present late for screening or diagnosis compared to men. ${ }^{12}$ This gender difference becomes very important in the setting of chronic non-communicable diseases as screening of asymptomatic individuals is very important for early diagnosis. Only $3 \%$ men and $1 \%$ women were diagnosed as diabetic during routine screening test. This highlights the need for better coverage of routine diabetes screening and preventive health check up in developing countries like Nepal.

The average of fasting blood sugar of women was higher in comparison to male indicating poorer levels of glycemic control. This is again attributable to the low emphasis placed on health of women. Previous studies have not shown major differences in the glycemic control between men and women. ${ }^{13}$ There could be some potential reasons for this disparity between studies in developed and developing countries. The most important being the social status of women in developing countries which is still poor. The parameter used to measure glycemic status in the previous studies was glycosylated hemoglobin which is a measure of blood sugar control over three months and is less susceptible to day to day variability in sugar levels. Whereas in the present study, the blood sugar level was assessed and is likely to reflect day to day variability. The third reason for this could be that the gender differences in care, support and self management reflects the difference in glycemic controls between men and women. In a study among Mexican Americans with type 2 diabetes it was observed that men had higher blood sugar levels compared to women. ${ }^{14}$ This is contrary to the findings of our study. A more robust measurement of glycemic levels and adjustment for other confounders could give a better picture of the gender differences in diabetes control.

Similar to the French population based study, this study revealed that both men and women follow similar trend of drug adherence. ${ }^{15}$ The analyses for healthful eating plan, average monthly eating plan and consumption of five servings of fruit and vegetables daily revealed that significantly lesser women were following these 
recommended healthy diet practices. ${ }^{16}$ Also women were straggling behind men in the recommended exercise for at least five days a week. ${ }^{17}$

Men were 0.328 times protected from bad dietary practices compared to women. Further stratified analysis revealed that self efficacy was an important confounder in the association between gender and dietary practices. Whereas men who had higher self efficacy had a better dietary practice, women with lower self efficacy couldn't follow good diet. The social dynamics of why women who have the control over the kitchen and food distribution in the household have poor self-efficacy when it comes to their own diabetes care is important to understand. In developing countries like Nepal women often play a dual role in the house. As much as they are home makers and intra-familiar food distributors, they are also bread winners in several families. But culturally women have a secondary position in the household where the men and children hold the primary position in terms of food distribution. This often leaves the healthy, which often is the more expensive foods, to the men and the left over less expensive foods for the women. The fatalistic attitudes attributed to women's health are another major reason for this unhealthy diet distribution in the family. This is the picture of the developing world where women neglect their own health. ${ }^{18}$ Social roles prevent women from practicing exercise. They have no time from their work. In addition customs and values bring upon hesitation and feeling of shyness to participate in physical exercise on par with men. ${ }^{19}$ Thus social structures and cultural beliefs play a huge role in restricting women from practicing self care behaviors.

The study shows low educational status of women similar with the national educational status of Nepal. ${ }^{20}$ A previous study showed that even in the lack of formal education when women are provided with short term disease specific education it results in improvements in self-management behaviour. ${ }^{21}$ In a similar study in the Malawi where GPs' gender sensitivity was stimulated by the training program and the supporting visits definite efficacy was demonstrated. Ideally, structural attention could be realized by embedding gender issues in existing organizational structures of general practices. ${ }^{22}$ Therefore despite these compelling social factors that can influence self-management behaviors there is scope for improving the diabetes self care situation of women through targeted health education and empowerment of women which according to the UN Secretary General Kofi Annan is the most effective tool for development.

\section{CONCLUSIONS}

The results of this study urge for the need of gender sensitive health education for women. Health promotion cannot be done in a 'one size fits all' model. There need to be gender specific and gender sensitive health promotion for diabetes prevention. It is evident from this study and from the socio-cultural milieu of the developing countries that the gender sensitive health promotion strategies are all the more important. Focus should be laid on improving the self efficacy of women.

Based on these findings there is a need to design gender specific and gender sensitive diabetes health education campaigns in the study area.

\section{ACKNOWLEDGMENTS}

The authors acknowledge the support and help of Dr. Basanta Kumar Tamrakar, Fishtail Hospital and Research Center, Pokhara, Dr. Sachin Dhakal, Western Regional Hospital, Pokhara and Ms. Sancheela Lama, School of Public Health, SRM University, India.

\section{REFERENCES}

1. International Diabetes Federation. [Online]. 2011 [cited 2012 Oct 22]; Available from: URL:http://www.idf.org/ diabetesatlas/5e/diabetes

2. Internationa Diabetes Federation. [Online]. 2011 [cited 2012 Oct 22]; Available from: URL:http://www.idf.org/ diabetesatlas/5e/south-east-asia

3. Juutilainen A, Kortelainen s, Lehto S, Rönnemaa T, Pyörälä K, Laakso M. Gender Difference in the Impact of Type 2 Diabetes on Coronary Heart Disease Risk. Diabetes Care. 2004 Dec;27(12):2898-904.

4. Bodenheimer T, Lorig K, Holman H, Grumbach K. Patient self-management of chronic disease in primary care. Journal of the American Medical Association. 2002 Nov 20;288(19):2469-75.
5. Grusec JE. Social learning theory and developmental psychology: the legacies of Robert Sears and Albert Bandura. Developmental Psychology. 1992;28(5):776-86

6. Schechter CB, Walker EA. Improving adherence to diabetes self-management recommendations. Diabetes Spectrum. 2002;15(3):170-5.

7. Zaidi SA. Gender perspectives and quality of care in underdeveloped countries: disease, gender and contextuality. Soc. Sci. Med. 1996;43(5):721-30.

8. Toobert DJ, Hampson SE, Glasgow RE. The summary of diabetes self-care activities measure: results from 7 studies and a revised scale. Diabetes Care. 2000 Jul;23(7):943-50. 
9. Diabetes Self-Management Program. [Online]. [cited 2012 Oct 22] Available from: URL:http://patienteducation. stanford.edu/programs/diabeteseng.html

10. Gucciardi E, Wang SC, DeMelo M, Amaral L, Stewart DE. Characteristics of men and women with diabetes: observations during patients' initial visit to a diabetes education centre. Can Fam Physician. 2008 Feb;54(2):219-27.

11. Kroenke K, Spitzer RL. Gender differences in the reporting of physical and somatoform symptoms. Psychosom Med. 1998 Mar-Apr;60(2):150-5.

12. Rani M, Bonu S. Rural Indian women's care-seeking behavior and choice of provider for gynecological symptoms. Stud Fam Plann. 2003 Sep;34(3):173-85.

13. Undén AL, Elofsson S, Andréasson A, Hillered E, Eriksson I, Brismar K. Gender differences in self-rated health, quality of life, quality of care, and metabolic control in patients with diabetes. Gend Med. 2008 Jun;5(2):162-80.

14. Brown SA, Harrist RB, Villagomez ET, Segura M, Barton SA, Hanis CL. Gender and treatment differences in knowledge, health beliefs, and metabolic control in Mexican Americans with type 2 diabetes. Diabetes Educ. 2000 May-Jun;26(3):425-38.

15. Tiv M, Viel JF, Mauny F, Eschwège E, Weill A, Fournier C et al. Medication Adherence in Type 2 Diabetes: The ENTRED Study 2007, a French Population-Based Study. PLoS ONE. [serial online] 2012 Mar 5 [cited Oct 22]; 7(3): e32412. Available from: URL:http://www.ncbi.nlm.nih.gov/pmc/ articles/PMC3293796/
16. American Diabetes Association, Bantle JP, Wylie-Rosett J, Albright AL, Apovian CM, Clark NG et al. Nutrition recommendations and interventions for diabetes: a position statement of the American Diabetes Association. Diabetes Care. 2008 Jan;31 Suppl 1:S61-78.

17. Sigal RJ, Kenny GP, Wasserman DH, Castaneda-Sceppa C. Physical activity/exercise and type 2 diabetes. Diabetes Care. 2004 Oct;27(10):2518-39.

18. Chorghade GP, Barker M, Kanade S, Fall $\mathrm{CH}$. Why are rural Indian women so thin? Findings from a village in Maharashtra. Public Health Nutr. 2006 Feb;9(1):9-18.

19. Lawton J, Ahmad N, Hanna L, Douglas M, Hallowell N. 'I can't do any serious exercise': barriers to physical activity amongst people of Pakistani and Indian origin with Type 2 diabetes. Health Educ Res. 2006 Feb;21(1):43-54.

20. Nepal Population report 2011. Kathmandu: Ministry of Health and Population Population Division; 2011.

21. Atak N, Gurkan T, Kose K. The effect of education on knowledge, self management behaviours and self efficacy of patients with type 2 diabetes. AJAN. 2008;26(2):66-74

22. Celik HH, Klinge II, Weijden TT, Widdershoven GG, Lagro-Janssen TA. Gender sensitivity among general practitioners: results of a training programme. BMC Med Educ. 2008 Jun 26;8:36 